\title{
PRODUKSI BIOFUEL DARI LIMBAH CPO DENGAN KATALIS BERBASIS TITANIUM OKSIDA DAN IMPLEMENTASINYA PADA PEMBELAJARAN KIMIA
}

\section{(Biofuel Production of CPO Waste With $\mathrm{Ni} / \mathrm{TiO}_{2}$ and $\mathrm{Co} / \mathrm{TiO}_{2}$ Catalyst and Implementation Of Chemical Learning)}

\author{
Nurlia Latipah $^{1^{*}}$, Agus Sundaryono ${ }^{2}$, Rina Elvia ${ }^{2}$ \\ ${ }^{1}$ Mahasiswa S-2 Pendidikan IPA FKIP Universitas Bengkulu \\ 2Dosen S-2 Pendidikan IPA FKIP Universitas Bengkulu \\ *nurlialatipah@gmail.com
}

\begin{abstract}
Conversion of CPO waste into biofuel is one of the efforts to find alternative energy to overcome Indonesia's energy crisis. The resulting methyl ester was further processed into biofuel by cracking process with $\mathrm{Ni} / \mathrm{TiO}_{2}$ and $\mathrm{Co} / \mathrm{TiO}_{2}$ catalysts at temperature $>350^{\circ} \mathrm{C}$ for 2.5 hours followed by distillation. Educational research was done by doing the learning process by using biofuel module. The optimum biofuel yield was obtained from cracking methyl ester with $5 \% \mathrm{Ni} / \mathrm{TiO}_{2}$ catalyst and $3 \% \mathrm{Co} / \mathrm{TiO}_{2}$ catalyst respectively of 66,67 and $61,90 \%$. The physical and chemical properties of cracked biofuels with $\mathrm{Ni} / \mathrm{TiO}_{2}$ and $\mathrm{Co} / \mathrm{TiO}_{2}$ catalysts have complied with ASTM standards for biofuel except acid numbers. There is an increase in student learning outcomes before and after using the module.
\end{abstract}

Keywords: CPO Waste, Sonochemistry, $\mathrm{Ni} / \mathrm{TiO}_{2}, \mathrm{Co} / \mathrm{TiO}_{2}$, Cracking, Biofuel, Module.

\begin{abstract}
ABSTRAK
Konversi limbah CPO menjadi biofuel merupakan salah satu upaya pencarian energi alternatif untuk mengatasi krisis energi Indonesia. Biofuel dihasilkan melalui melalui proses cracking metil ester dengan katalis $\mathrm{Ni} / \mathrm{TiO}_{2}$ dan $\mathrm{Co} / \mathrm{TiO}_{2}$ pada suhu $>350^{\circ} \mathrm{C}$ selama $2,5 \mathrm{jam}$ dilanjutkan dengan destilasi. Penelitian pendidikan dilakukan dengan melakukan proses pembelajaran dengan menggunakan modul biofuel dari limbah CPO. Rendemen biofuel optimum dihasilkan dari cracking metil ester dengan katalis $5 \% \quad \mathrm{Ni} / \mathrm{TiO}_{2}$ dan katalis $3 \%$ $\mathrm{Co} / \mathrm{TiO}_{2}$ masing-masing sebanyak 66,67 dan 61,90\%. Sifat fisik dan kimia biofuel hasil cracking dengan katalis $\mathrm{Ni} / \mathrm{TiO}_{2}$ dan $\mathrm{Co} / \mathrm{TiO}_{2}$ telah sesuai standar ASTM untuk biofuel kecuali angka asam. Terdapat peningkatan hasil belajar mahasiswa sebelum in setelah menggunakan modul.
\end{abstract}

Kata kunci: Limbah CPO, Sonochemistry, $\mathrm{Ni} / \mathrm{TiO}_{2}, \mathrm{Co} / \mathrm{TiO}_{2}$, Cracking, Biofuel, Modul.

\section{PENDAHULUAN}

Bahan Bakar Minyak (BBM) sebagai salah satu daya dukung kehidupan manusia terus mengalami peningkatan akan kebutuhannya seiring dengan adanya peningkatan jumlah penduduk dari tahun ke tahun. Keadaan ini mengakibatkan para ilmuan mengembangkan sumber-sumber energi alternatif yang diharapkan mampu mengatasi krisis energi di masa yang akan datang.

Indonesia dengan wilayahnya yang sangat subur menjadi salah satu negara penghasil kelapa sawit terbesar di dunia. Kondisi ini memungkinkan Indonesia untuk dapat mengasilkan sumber energi alternatif yang berasal dari sawit. Proses esterifikasi dan transesterifikasi minyak kelapa sawit ternyata mampu menghasilkan bahan bakar minyak. Bahan bakar dari minyak sawit lebih ramah 
lingkungan karena bebas nitrogen dan sulfur. Selain itu kandungan asam oleat yang mencapai $55 \%$ dalam minyak sawit cukup dijadikan bahan pertimbangan untuk menggunakan minyak sawit sebagai bahan baku pembuatan bahan bakar nabati (Nugroho, 2014).

Kandungan minyak yang masih terdapat pada limbah cair kelapa sawit juga memungkinkan limbah kelapa sawit untuk dapat diolah lebih lanjut sehingga dihasilkan bahan bakar minyak.

Bahan bakar yang terbuat dari minyak nabati atau lemak hewan biasa dikenal dengan metil ester. Campuran mono-alkyl ester dari rantai panjang asam lemak sebagai penyusun metil ester memiliki sifat kimia dan fisika yang sama dengan minyak bumi. Hal ini yang menjadikan metil ester dapat dijadikan bahan bakar alternatif pengganti minyak bumi. Kandungan sulfur yang sangat sedikit pada metil ester mengakibatkan bahan bakar alternatif ini termasuk dalam bahan bakar ramah lingkungan (Arita dkk, 2008).

Reaksi esterifikasi untuk menghasilkan metil ester dilakukan dengan mereaksikan trigliserida dengan metanol. Senyawa ester dihasilkan melalui reaksi transesterifikasi dengan bantuan katalis. Reaksi ini berlangsung lambat, berkisar 4-8 jam menggunakan banyak katalis dan alkohol (Satriadi, 2014). Guna menghindari suhu yang tinggi dan lamanya waktu reaksi, maka pembuatan metil ester memanfaatkan gelombang ultrasonik.

Istilah cracking atau perengkahan dipakai untuk menjelaskan terjadinya pemotongan senyawa hidrokarbon menjadi lebih pendek dengan cara memotong ikatan antar karbon dalam senyawa tersebut. Cracking dapat terjadi melalui mekanisme terbentuknya ion karbonium sebagai radikal bebas pada suhu yang relatif tinggi, namun reaksi cracking dapat dipercepat oleh kekuatan asam yang ditunjukkan oleh kemampuan transfer proton (Nasikin dkk, 2010). Inti asam Bronsted pada katalis berperan untuk merengkah ikatan rangkap (asam oleat) sedangkan inti asam Lewis berperan untuk merengkah ikatan tunggal (asam palmiat) pada struktur trigliserida minyak kelapa sawit.

$\mathrm{TiO}_{2}$ merupakan katalis support yang bersifat asam dan masih stabil pada suhu tinggi. Titanium dioksida memiliki potensi untuk digunakan dalam produksi energi fotokatalis, dapat melakukan reaksi pemecahan air dan mendegradasi senyawa organik (Fatimah dan Wijaya, 2005). $\mathrm{TiO}_{2}$ memiliki luas permukaan 10 $\mathrm{m}^{2} / \mathrm{g}$ sampai $50 \mathrm{~m}^{2} / \mathrm{g}$ (Satterfield, 1991). Sifat asam pada $\mathrm{TiO}_{2}$, luas permukaannya yang besar, harganya yang murah, mudah dalam penyiapannya dan stabil pada suhu tinggi menarik perhatian peneliti untuk menggunakannya sebagai katalis pada proses cracking metil ester. Kemampuan $\mathrm{TiO}_{2}$ untuk memecah air menjadi oksigen dan hidrogen diharapkan mampu menurunkan kadar air dari hasil cracking yang biasanya masih sangat tinggi.

Partikel padatan oksida seperti $\mathrm{TiO}_{2}$ umumnya tidak stabil dan cenderung membentuk agregat sehingga menurunkan aktivitas katalitiknya. Masalah tersebut dapat diatasi dengan mendispersikan komponen katalis logam pada $\mathrm{TIO}_{2}$ sehingga dihasilkan katalis berpengemban.. Logam yang biasa digunakan sebagai katalis pengemban adalah logam transisi (Wardhani, 2008). Logam transisi yang diembankan ke $\mathrm{TiO}_{2}$ dapat bertindak sebagai penangkap elektron, hal ini dikarenakan logam transisi merupakan unsur golongan $B$ yang mempunyai orbital $d$ yang belum terisi penuh penuh. Orbital $d$ yang belum terisi penuh mengakibatkan unsur golongan transisi memiliki sifat aktivitas katalitik (Sudjana dkk, 2002).

Pada penelitian ini logam Ni dipilih sebagai logam yang akan di impregnasi pada permukaan $\mathrm{TiO}_{2}$ karena $\mathrm{Ni}$ cukup efektif dan memberikan kontribusi positif terhadap aktivitas katalis. Aktifitas tersebut diharapkan mampu memodifikasi sifat $\mathrm{TiO}_{2}$ sebagai fotokatalitik semikonduktor untuk dapat melakukan reaksi cracking. $\mathrm{Ni}$ juga memiliki sifat keasaman yang tinggi (Sartika dkk, 2014) sehingga dapat berperan sebagai katalis yang dibutuhkan untuk reaksi cracking.

Logam Co juga dipilih sebagai dopan karena di beberapa penelitian Co 
mampu meningkatkan reaksi fotodegradasi dan selective terhadap senyawa organik. Dopan Co terhadap $\mathrm{TiO}_{2}$ juga lebih aktif jika dibandingkan $\mathrm{TiO}_{2}$ murni (Amadelli dkk, 2008). Pengembanan logam $\mathrm{CoO}$ dan $\mathrm{CoO}-\mathrm{MoO}$ ke dalam pori ZnO-ZAA menaikkan keasaman katalis. Hal ini menunjukkan logam mempunyai situs asam, yaitu situs asam Lewis yang dapat mengadsorbsi basa amoniak (Trisunaryanti, 2008). Situs asam Lewis yang terdapat pada katalis $\mathrm{Co} / \mathrm{TiO}_{2}$ diharapkan mampu untuk merengkah ikatan tunggal (asam palmiat) pada struktur metil ester sehingga dihasilkan biofuel dengan rantai karbon yang lebih pendek.

Katalis $\mathrm{Ni} / \mathrm{TiO}_{2}$ dan $\mathrm{Co} / \mathrm{TiO}_{2}$ dengan sifat semikonduktornya dan kemampuan fotokatalitiknya diharapkan mampu melakukan proses cracking terhadap metil ester yang dibuat dengan menggunakan bantuan gelombang ultrasonik pada penelitian yang akan dilakukan. Hasil penelitian ini nantinya akan dijadikan sumber dalam pembuatan modul pembelajaran sebagai salah satu sumber belajar bagi mahasiswa semester IV pada mata kuliah Kimia Organik II.

Modul yang dikembangkan dari hasil penelitian perlu menyajikan faktafakta nyata didukung stimulus berupa gambar/tabel karena dapat menarik perhatian mahasiswa untuk mempelajarinya (Parmin dan Peniati, 2012).

Pemanfaatan hasil penelitian sebagai sumber belajar dapat memberikan pengalaman nyata bagi mahasiswa. Keuntungan yang diperoleh dari pembelajaran dengan menggunakan modul adalah menumbuhkan motivasi belajar mahasiswa, mengarahkan konsepsi mahasiswa menuju konsep ilmiah sehingga hasil belajar mahasiswa dapat ditingkatkan seoptimal mungkin secara kuantitas dan kualitas.

Modul yang dikembangkan dengan memanfaatkan hasil penelitian akan menghubungkan keterkaitan antara fakta yang diperoleh dari pengumpulan data, konsep dari kajian teori, prosedur, dan prinsip yang terkandung dalam materi pembelajaran.

\section{METODE PENELITIAN}

\section{Persiapan Sampel}

Limbah CPO diambil dari kolam pertama PT. Bio Nusantara Teknologi. Limbah CPO dipanaskan kemudian disaring. Degumming dilakukan dengan menambahkan $\mathrm{H}_{3} \mathrm{PO}_{4} \quad 0,6 \%$ sebanyak 1$3 \%$ dari berat minyak. Bleaching dilakukan dengan menambahkan zeolit aktif sebanyak $10 \%$ dari berat minyak, campuran diaduk dengan magnetic stirer kemudian disaring dengan kertas saring.

\section{Konversi minyak dari limbah CPO menjadi metil ester}

Limbah yang telah melalui proses bleaching selanjutnya diesterifikasi untuk menurunkan kadar asam lemak bebas (ALB). Esterifikasi dilakukan dengan bantuan katalis asam yang bersumber dari $\mathrm{H}_{2} \mathrm{SO}_{4}$, sedangkan transesterifikasi dilakukan dengan bantuan katalis basa yang bersumber dari $\mathrm{NaOH}$.

\section{Pembuatan Katalis}

Katalis $\mathrm{Ni} / \mathrm{TiO}_{2}$ dibuat dengan cara: sebanyak $10 \mathrm{~g} \mathrm{TiO}_{2}$ dan $0,5 \mathrm{~g} \mathrm{NiCl}_{2}$ dilarutkan dalam $20 \mathrm{ml}$ aquadest, di aduk dengan magnetik stirer selama 30 menit, diultrasonikasi selama 30 menit pada suhu $60^{\circ} \mathrm{C}$, diaduk kembali dengan magnetik strirrer pada suhu $80-90^{\circ} \mathrm{C}$, dimasukkan ke dalam oven dengan suhu $110^{\circ} \mathrm{C}$ untuk menguapkan air yang terdapat dalam larutan, dikalsinasi pada suhu $300^{\circ} \mathrm{C}$ selama 2 jam di dalam Furnance, dan dihaluskan dengan menggunakan alu dan lumpang untuk selanjutnya digunakan dalam proses cracking (modifikasi dari Afrozi, 2010).

Katalis $\mathrm{Co} / \mathrm{TiO}_{2}$ dibuat dengan cara: $\begin{array}{llllll}\text { sebanyak } & 10 & \mathrm{~g} & \mathrm{TiO}_{2} & \text { dan } 2 & \mathrm{~g}\end{array}$ $\mathrm{Co}\left(\mathrm{CH}_{3} \mathrm{COO}\right)_{2} \cdot 4 \mathrm{H}_{2} \mathrm{O}$ dilarutkan dalam 20 $\mathrm{ml}$ aquadest, diultrasonikasi selama 10 menit, diaduk dengan magnetik strirrer selama 2 jam, dipanaskan dalam oven pada suhu $100^{\circ} \mathrm{C}$ selama 2 jam, dikalsinasi pada suhu $300^{\circ} \mathrm{C}$ selama 30 menit di dalam Furnance, dan dihaluskan dengan menggunakan alu dan lumpang 
untuk selanjutnya digunakan dalam proses cracking. (modifikasi dari Amadelli dkk, 2008)

\section{Cracking Katalitik Metil Ester menggunakan katalis $\mathrm{Ni} / \mathrm{TiO}_{2}$ dan $\mathrm{Co} / \mathrm{TiO}_{2}$.}

Proses cracking dilakukan dengan Variasi berat katalis yaitu $1 \%, 3 \%$, dan $5 \%$ dari berat metil ester. Proses ini dilakukan dengan cara menambahkan katalis pada metil ester dalam labu peralatan refluks. Tambahkan juga batu didih kedalamnya. Campuran dipanaskan pada suhu $380^{\circ} \mathrm{C}$ selama 2 jam di atas kompor dengan pasir sebagai konduktor panas. Selanjutnya hasil yang didapat didestilasi pada suhu yang sama untuk memisahkan biofuel. Biofuel yang dihasilkan ditentukan komponen senyawa-senyawa kimia yang terdapat didalamnya dengan menggunakan alat kromatografi gasspektroskopi massa (GC-MS) dan diuji sisat fisik dan kimianya meliputi densitas, viscositas, titik tuang, titik kabut, dan angka asam.

\section{Menentukan perbedaan hasil belajar mahasiswa sebelum dan setelah menggunakan modul}

Penelitian ini dimulai dilakukan dengan tahapan: penyusunan draft modul, validasi modul, perbaikan perangkat modul, pembuatan soal-soal pretes dan postes, uji coba instrumen soal pretes, melakukan analisis terhadap hasil uji coba, uji validitas, uji reliabilitas, uji tingkat kesukaran, uji daya beda, pelaksanaan pembelajaran dan analisis data. Data pretes dan postes kelas yang diperoleh diuji homogenitasnya dengan uji Saphiro Wilk lalu diuji normalitasnya dengan uji Kolmogorov-Smirnov. Jika data normal akan dilanjutkan dengan uji-t (paired sample T-test) guna melihat daya beda antara pretes dan postes. Apabila data tidak normal akan dilanjutkan dengan uji peringkat bertanda wilcoxon.

\section{Hasil Dan Pembahasan}

tahap $\begin{gathered}\text { Limbah CPO yang telah melalui } \\ \text { penyaringan, pemansan, }\end{gathered}$ degumming, bleaching, esterifikasi, dan transesterifikasi menghasilkan metil ester dengan rendemen 87,8\%. Metil ester yang telah melalui proses cracking selanjutnya di destilasi untuk mendapatkan biofuel.

Tabel 1. Rendemen hasil cracking

\begin{tabular}{|l|l|l|l|l|}
\hline No & Jenis & \multicolumn{1}{|c|}{$\begin{array}{c}\text { Berat } \\
\text { katalis }\end{array}$} & $\begin{array}{c}\text { Berat } \\
\text { katalis } \\
\text { biofuel } \\
(\mathrm{g})\end{array}$ & $\begin{array}{c}\% \text { hasil } \\
\text { cracking }\end{array}$ \\
\hline \multirow{3}{*}{1} & \multirow{2}{*}{$\mathrm{Ni} / \mathrm{TiO} 2$} & $1 \%$ & 12,6 & 60,00 \\
\cline { 3 - 5 } & & $3 \%$ & 12,4 & 59,64 \\
\cline { 3 - 5 } & & $5 \%$ & 14 & 66,67 \\
\hline \multirow{2}{*}{2} & \multirow{2}{*}{$\mathrm{Co} / \mathrm{TiO} 2$} & $1 \%$ & 7,5 & 35,71 \\
\cline { 3 - 5 } & & $3 \%$ & 13 & 61,90 \\
\cline { 3 - 5 } & & $5 \%$ & 9,5 & 45 \\
\hline
\end{tabular}

Tabel 1 menunjukkan Penggunaan berat katalis $1 \%$, $3 \%$, dan $5 \% \mathrm{Ni} / \mathrm{TiO}_{2}$ memberikan perbedaan jumlah rendemen yang cukup kecil. Nilai rendemen 3\% katalis $\mathrm{Ni} / \mathrm{TiO}_{2}$ lebih rendah bila dibandingkan $1 \%$ dan $5 \%$ katalis $\mathrm{Ni} / \mathrm{TiO}_{2}$. Penurunan nilai ini dapat diakibatkan karena pemanas yang digunakan kurang stabil sehinggan mengakibatkan sintering. Sintering ditandai dengan penurunan jumlah produk yang tidak terlalu signifikan (Nasikin dan Susanto, 2010).

Sementara penggunaan berat katalis $1 \%, 3 \%$, dan $5 \%$ katalis $\mathrm{Co} / \mathrm{TiO}_{2}$ memberikan perbedaan jumlah rendemen yang cukup besar. Tabel 1 menunjukkan bahwa penggunaan $1 \% \quad \mathrm{Co} / \mathrm{TiO}_{2}$ memberikan nilai rendemen yang sangat kecil bila dibandingkan dengan penggunaan $3 \%$ dan $5 \%$ katalis $\mathrm{Co} / \mathrm{TiO}_{2}$. Hal ini dapat diakibatkan jumlah katalis yang digunakan tidak mencukupi untuk dapat melakukan reaksi cracking sehingga banyak metil ester yang tidak tercracking. Penurunan nilai rendemen pada saat penggunaan $5 \%$ katalis $\mathrm{Co} / \mathrm{TiO}_{2}$ bila dibandingkan dengan penggunaan 3\% katalis $\mathrm{Co} / \mathrm{TiO}_{2}$ dapat diakibatkan terjadinya deaktivasi katalis akibat sintering (hilangnya permukaan aktif karena pertumbuhan kristal), keracunan (tertutupnya inti aktif karena adsorbsi kimia yang kuat) (Nasikin dan Susanto, 2010).

Menurut Nasikin dan Susanto
(2010) reaksi cracking terjadi karena 
keberadaan ion karbonium pada posisi tertentu di atom karbon dalam senyawa hidrokarbon. Ion karbonium lebih mudah terbentuk pada olefin daripada parafin. Kandungan asam oleat pada metil ester yang dicracking mengakibatkan ion karbonium akan lebih mudah terbentuk sehingga senyawa tersebut akan tercracking menjadi senyawa yang lebih pendek. Fraksi hidrokarbon dengan senyawa yang lebih pendek dari metil ester adalah fraksi bensin, kerosin dan solar.

Uji sifat fisik dan kimia biofuel hasil cracking katalitik dengan katalis $\mathrm{Ni} / \mathrm{TiO}_{2}$ dan $\mathrm{Co} / \mathrm{TiO}_{2}$ dilakukan untuk mengetahui mutu dari biofuel yang dihasilkan. Secara umum, hasil pengujian sifat fisik dan kimia biofuel hasil cracking katalitik tertera pada tabel 3.

Tabel 2. Sifat fisika dan kimia biofuel hasil cracking dengan katalis $\mathrm{Ni} / \mathrm{TiO}_{2}$ dan $\mathrm{Co} / \mathrm{TiO}_{2}$

\begin{tabular}{|c|c|c|c|c|}
\hline \multirow[b]{2}{*}{$\begin{array}{l}\text { Paramet } \\
\text { er }\end{array}$} & \multirow[b]{2}{*}{$\begin{array}{l}\text { Satu } \\
\text { an }\end{array}$} & \multicolumn{2}{|c|}{$\begin{array}{c}\text { Biofuel hasil } \\
\text { cracking }\end{array}$} & \multirow{2}{*}{$\begin{array}{l}\text { Stand } \\
\text { ar } \\
\text { ASTM } \\
\text { biofue } \\
\text { । D } \\
6751 \\
\text { (B100 }\end{array}$} \\
\hline & & $\begin{array}{l}\text { Deng } \\
\text { an } \\
\text { katalis } \\
\mathrm{Ni} / \mathrm{TiO} \\
2\end{array}$ & $\begin{array}{l}\text { Deng } \\
\text { an } \\
\text { katalis } \\
\mathrm{Co} / \mathrm{Ti} \\
\mathrm{O}_{2}\end{array}$ & \\
\hline $\begin{array}{l}\text { Densita } \\
\mathrm{s}\end{array}$ & $\begin{array}{l}\mathrm{g} / \mathrm{cm} \\
3\end{array}$ & $\begin{array}{l}0,819 \\
9\end{array}$ & $\begin{array}{l}0,803 \\
9\end{array}$ & $\begin{array}{l}\text { Maks } \\
0,9\end{array}$ \\
\hline $\begin{array}{l}\text { Viskosit } \\
\text { as }\end{array}$ & Cst & $\begin{array}{l}1,683 \\
7\end{array}$ & $\begin{array}{l}1,914 \\
4\end{array}$ & $\begin{array}{l}\text { Maks } \\
7\end{array}$ \\
\hline $\begin{array}{l}\text { Titik } \\
\text { tuang }\end{array}$ & ${ }^{\circ} \mathrm{C}$ & 0 & 0 & $\begin{array}{l}\text { Maks } \\
16\end{array}$ \\
\hline $\begin{array}{l}\text { Titik } \\
\text { kabut }\end{array}$ & ${ }^{\circ} \mathrm{C}$ & 9,4 & 1,23 & $\begin{array}{ll}-3 & s d \\
12 & \end{array}$ \\
\hline $\begin{array}{l}\text { Angka } \\
\text { asam }\end{array}$ & $\begin{array}{l}\mathrm{mg} \\
\mathrm{KOH} / \mathrm{g} \\
\text { Biofuel }\end{array}$ & 9,14 & 8,41 & $\begin{array}{l}\text { Maks } \\
0,8\end{array}$ \\
\hline
\end{tabular}

\section{Menentukan Perbedaan Hasil Belajar Mahasiswa Sebelum dan setelah Menggunakan Modul}

Penelitian pendidikan dilakukan terhadap mahasiswa semester 4 Pendidikan Kimia Fakultas Keguruan dan Ilmu Pendidikan Universitas Bengkulu pada mata kuliah Kimia Organik II. Mahasiswa yang dilibatkan untuk sampel uji coba berjumlah 18 orang. Instrumen penelitian berupa Modul Biofuel dari Limbah CPO yang dikembangkan dari hasil penelitian yang berjudul Cracking Metil Ester Limbah CPO Hasil Sonochemistry Menjadi Biofuel Dengan Katalis $\mathrm{Co} / \mathrm{TiO}_{2}$ dan $\mathrm{Ni} / \mathrm{TiO}_{2}$.

Hasil uji validitas, reliabilitas, taraf kesukaran, dan daya beda digunakan untuk menentukan soal yang akan digunakan pada penelitian. Sebanyak 10 soal yang memenuhi kriteria valid, reliabel, tingkat kesukaran sedang dan daya pembeda baik digunakan untuk penelitian. Hasil postes yang dibandingkan dengan hasil pretes menunjukkan bahwa $100 \%$ mahasiswa mengalami peningkatan hasil belajar. Nilai rata-rata pretes pada penelitian ini adalah 35,5 sedangkan nilai rata-rata postes adalah 83,5. Hasil pretes dan postes ditunjukkan pada gambar 4.7.

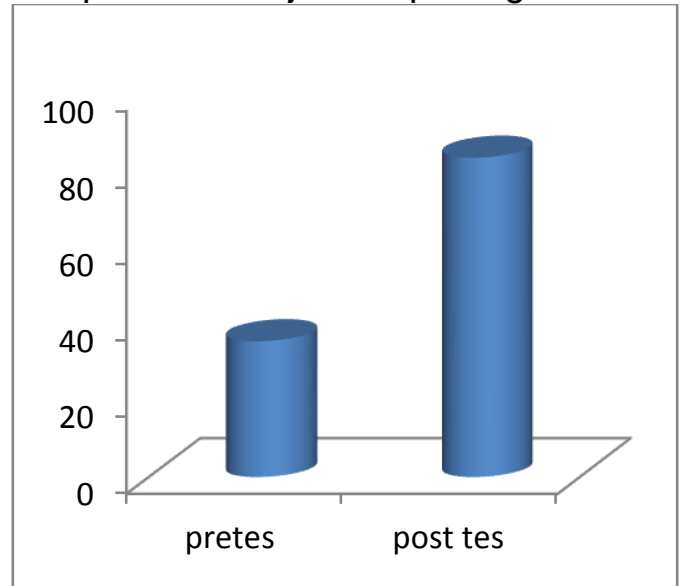

Gambar 4.7. Grafik rata-rata nilai pretes dan postes

Modul sebagai sumber belajar memiliki keunggulan dibanding buku teks pada umumnya. Modul memiliki keterangan bagaimana mempelajari materi maupun kegiatan yang ada di dalamnya sehingga siswa dapat belajar secara mandiri. Gambar dan ilustrasi yang menarik pada modul menimbulkan ketertarikan siswa mempelajari modul (Purnomo dkk, 2013).

Pemanfaatan modul dalam proses pembelajaran dapat menjadi salah satu alternatif variasi proses pembelajaran guna meningkatkan hasil belajar siswa atau mahasiswa. 


\section{Kesimpulan}

Rendemen biofuel terbanyak yang dihasilkan dari cracking metil ester limbah CPO dengan katalis $\mathrm{Ni} / \mathrm{TiO}_{2}$ dan $\mathrm{Co} / \mathrm{TiO} 2$ yaitu sebesar $66,67 \%$ dan $61,50 \%$. Kualitas biofuel dari hasil cracking metil ester limbah CPO dengan katalis $\mathrm{Ni} / \mathrm{TiO}_{2}$ dan $\mathrm{Co} / \mathrm{TiO}_{2}$ sudah memenuhi standar biofuel. Namun angka asamnya masih sangat tinggi. Hasil Belajar mahasiswa setelah menggunakan modul lebih tinggi jika dibandingkan hasil belajar sebelum menggunakan modul.

\section{Saran}

Penelitian selanjutnya sangat baik jika katalis $\mathrm{Ni} / \mathrm{TiO} 2$ dan $\mathrm{Co} / \mathrm{TiO} 2$ dianalisa tentang keasaman, luas permukaan spesifik, volume pori, jari-jari pori agar diketahui karakternya sebagai pendukung keberhasilan katalis dalam reaksi cracking.

\section{DAFTAR PUSTAKA}

Amadelli R, Samiolo L, Maldotti A, Molinari A, Valigi M, Gazzoli D. 2008. Preparation, Characterisation, and Photocatalytic Behaviour of Co$\mathrm{TiO}_{2}$ with Visible Light Respone. Hindawi Publishing Corporation International of Photoenergy

Arita S, Dara M B, Irawan J. 2008. Pembuatan Metil ester Asam Lemak Dari CPO Off Grade Dengan Metode Esterifikasi-
Transesterifikasi. Jurnal Teknik Kimia, No 2 vol 15

Nasikin M, Susanto B H. 2010. Katalisis Heterogen. Ul-Press

Nugroho, A M P, Fitriyanto D, Roesyadi A.(2014). Pembuatan Biofuel dari Minyak Kelapa Sawit Melalui Proses Hydrocracking dengan Katalis $\mathrm{Ni}-\mathrm{Mg} / \mathrm{\gamma}-\mathrm{Al}_{2} \mathrm{O}_{3}$. Jurnal Teknik POMITS Vol 3 No. 2

Parmin, Peniati. E. 2012. Pengembangan Modul Mata Kuliah Strategi Belajar Mengajar IPA Berbasis Hasil Penelitian Pembelajaran. JPII 1 (1): 8-15

Sartika G, Muwarni IK, 2014. Sintesis dan karakterisasi Katalis $\mathrm{Mg}_{1-x} \mathrm{Ni}_{x} \mathrm{~F}_{2 \pm \delta}$. Jurnal Sains dan Seni Pomits. Vol 3 N0 2. 2337-3520

Satterfield C N. 1991. Heterogenous Catalysis In Industrial Practice Second Edition. McGraw-Hill, Inc.

Sudjana E, Abdurachman M, Yuliasari Y. 2002. Karakterisasi Senyawa Kompleks Logam Transisi Cr, Mn, dan ag dengan Glisin Melalui Spektrofotometri Ultraungu dan Sinar Tampak. Jurnal Bonatura Vol 4 No 2;69-86

Wardhani S, Purwonugroho D, Mardiana D. 2008. Phenol Oxidation Using Natural Zeolite supported Metal lon Catalyst (Oksidasi Fenol Menggunakan Katalis Ion Logam Berpendukung Zeolit Alam). Indo. J. Chem, 8 (2), 215-218 